\title{
REFLEXIONES SOBRE LAS APROXIMACIONES Y DISTANCIAS ENTRE HERMENÉUTICA Y HERMENÉUTICA DE PROFUNDIDAD COMO MARCO TEÓRICO PARA LOS ESTUDIOS HISTORIOGRÁFICOS EN EDUCACIÓN MATEMÁTICA
}

\author{
Alexandre Ausani Huff ${ }^{1}$ \\ alexandre.a.huff@gmail.com \\ https://orcid.org/0000-0001-5693-9226 \\ Arno Bayer ${ }^{1}$ \\ arnob@ulbra.br \\ https://orcid.org/0000-0001-7721-1162 \\ Fernando Luís de Rosso ${ }^{1}$ \\ fernandol.rosso@gmail.com \\ https://orcid.org/0000-0003-2275-9619 \\ ${ }^{1}$ Universidad Luterana de Brasil, ULBRA \\ Rio Grande do Sul, Brasil
}

Recibido: 15/02/2020 Aceptado: 22/04/2020

\section{Resumen}

La investigación en Historia y Educación Matemática siempre ha planteado dudas sobre los procedimientos metodológicos. Es de destacar que un procedimiento metodológico consistente no debe perder de vista principalmente el lenguaje, las condiciones de vida y el concepto del mundo, que experimentan cambios con el tiempo. Las declaraciones relevantes, que son parte de la historia, deben ser traídas al presente para que puedan ser entendidas en su tiempo a la luz de nuestro tiempo. Es por eso que es necesario estudiar y conocer la hermenéutica y las bases del pensamiento hermenéutico, construyendo bases filosóficas conceptuales e históricas, de modo que con estos argumentos, sea posible construir los puentes necesarios entre la hermenéutica, la historicidad y la enseñanza de las matemáticas. Por lo tanto, este artículo tiene la intención de presentar la posibilidad de hacer esta articulación factible y, por lo tanto, ofrecer subsidios para aquellos que investigan la Historia de las Matemáticas y la Historia de la Enseñanza de las Matemáticas y quienes, a veces, encuentran difícil basar sus estudios con respecto a la escritura. Así como para interpretar hechos históricos relevantes en el contexto de la investigación académica. A lo largo del texto, realizaremos un breve rescate histórico de la hermenéutica, y también la contextualización como sus posibilidades de aplicación en los estudios académicos.

Palabras clave: Hermenéutica. Profundidad de la hermenéutica. Investigación historiográfica. Educación Matemática. Enseñanza de las matemáticas. 


\title{
REFLEXÕES ACERCA DAS APROXIMAÇÕES E DISTANCIAMENTOS ENTRE A HERMENÊUTICA E A HERMENÊUTICA DE PROFUNDIDADE COMO REFERENCIAL TEÓRICO PARA ESTUDOS HISTORIOGRÁFICOS EM EDUCAÇÃO MATEMÁTICA
}

\begin{abstract}
Resumo
A Pesquisa em História e Educação Matemática sempre suscitou dúvidas quanto aos procedimentos metodológicos. Destaca-se que um procedimento metodológico consistente não deve perder de vista principalmente a linguagem, as condições de vida e a concepção de mundo, as quais sofrem mudanças ao longo do tempo. Enunciados relevantes, que fazem parte da história, devem ser trazidos ao presente de forma que possam ser compreendidos no seu tempo à luz do nosso tempo. Por isso se faz necessário estudar e conhecer a hermenêutica e as bases do pensamento hermenêutico, construindo conceitualmente e historicamente bases filosóficas, para que com esses argumentos, se possa construir pontes necessárias entre a hermenêutica, a historicidade e o ensino da matemática. Assim, este artigo pretende apresentar uma possibilidade para viabilizar esta articulação e assim oferecer subsídios para aqueles que pesquisam a História da Matemática e a História do Ensino da Matemática e que, por vezes, encontram dificuldades para fundamentar os seus estudos no que se refere à escrita histórica, bem como para interpretar fatos históricos relevantes na contextualização de pesquisas acadêmicas. No decorrer do texto, realizaremos um breve resgate histórico da Hermenêutica, e também a contextualização enquanto as suas possibilidades de aplicação em estudos acadêmicos.

Palavras chave: Hermenêutica. Hermenêutica de Profundidade. Pesquisa Historiográfica. Educação Matemática. Ensino da Matemática.

\section{REFLECTIONS ABOUT APPROXIMATIONS AND DISTANCING BETWEEN HERMENEUTICS AND HERMENEUTICS OF DEPTH AS THEORETICAL FRAMEWORK FOR HISTORIOGRAPHIC STUDIES IN MATHEMATICAL EDUCATION}

\begin{abstract}
Research in History and Mathematical Education has always raised doubts about methodological procedures. It is noteworthy that a consistent methodological procedure must not lose sight mainly of language, living conditions and the concept of the world, which undergo changes over time. Relevant statements, which are part of history, must be brought to the present so that they can be understood in their time in the light of our time. That is why it is necessary to study and know hermeneutics and the bases of hermeneutic thinking, constructing conceptually and historically philosophical bases, so that with these arguments, it is possible to build necessary bridges between hermeneutics, historicity and the teaching of mathematics. Thus, this article intends to present a possibility to make this articulation feasible and thus offer subsidies for those who research the History of Mathematics and the History of the Teaching of Mathematics and who, at times, find it difficult to base their studies with regard to writing history, as well as to interpret relevant historical facts in the context of academic research. Throughout the text, we will carry out a brief historical review of Hermeneutics, as well as contextualizing it as its possibilities of application in academic studies. Keywords: Hermeneutics. Depth Hermeneutics. Historiographical Research. Mathematical Education. Mathematics teaching.
\end{abstract}




\section{Introdução}

Os Estudos Historiográficos em Educação Matemática mostram-se desafiadores para os pesquisadores que não possuem formação específica nesta área de conhecimento sendo que, por vezes, doses de dúvidas e incertezas pairam sobre o pensamento daqueles que se propõem a enfrentar tal desafio. Em virtude disso nos propusemos a, neste artigo, discutir aproximações, distanciamentos, e caminhos que tanto a Hermenêutica, quanto a Hermenêutica de Profundidade nos apresentam como referencial teórico para investigações neste campo de pesquisa.

As ideias de Valente (2002) apresentam a Matemática como uma disciplina escolar que, durante significativo período ficou esquecida pelos pesquisadores da História da Educação. Assim, com seus estudos, este autor, aponta para uma transformação deste campo de pesquisas através da ação dos investigadores da didática do Ensino da Matemática, os quais trazem consigo a intenção de aprofundar seus trabalhos através de um viés histórico e, ainda, pela relevância dada pelos historiadores da disciplina, os quais perceberam neste campo de pesquisa uma importante abertura inclusive para o desenvolvimento da mesma como área de estudo, a qual, escolheu-se como campo de trabalho.

Os estudos de perspectiva historiográfica, via de regra, tentam mostrar que tudo aquilo que ajudou, com o passar do tempo, na construção de uma trajetória, ajuda também a explicar o agora ou, os fatos e contextos, bem como suas produções, que precedem períodos que se deseja pesquisar, os quais têm tanta importância quanto aquele que ocorre neste espaço temporal em que acontece essa reflexão. É necessário, portanto, para que o estudo historiográfico seja válido, a recriação dos contextos social e histórico em que os objetos de análise foram produzidos e utilizados.

Acontece que, para que isto seja possível, faz-se necessária a escolha de uma metodologia capaz de arranjar todas estas perspectivas e que isto possa se estruturar por meio da história, seus fatos e contextos. Além de tudo isso, essa estrutura de contextualização, precisa ser interpretada e reescrita através de uma narrativa concisa, crescente e de boa fundamentação, trazida aos leitores e pesquisadores da área.

Deste modo, apresentamos a discussão de duas possibilidades metodológicas: a Hermenêutica e a Hermenêutica de Profundidade, como possíveis referenciais para esta categoria de estudo as quais, conforme nosso entendimento trazem elementos relevantes 
quando se faz necessário fundamentar um estudo historiográfico, visto que, além de nos possibilitar a interpretação dos fatos e/ou escritos, nos proporciona ainda a alternativa analítica dos contextos que os envolveram. Este artigo é fruto de uma reflexão sobre duas dissertações de mestrado, defendidas no ano de 2018, as quais nos ofereceram elementos para este artigo.

\section{A Hermenêutica}

Antes de tudo, porém, é fundamental o desenvolvimento de uma definição da hermenêutica e do pensamento hermenêutico, constituindo assim conceitualmente e historicamente as suas bases filosóficas e, com esses argumentos, construir as pontes necessárias entre a hermenêutica, a historicidade e o ensino da matemática.

Trabalharemos então, a partir deste momento, as características da hermenêutica, utilizando como referência os estudos de Strecker; Schnelle (1997) os quais relatam o surgimento da Hermenêutica a partir do século I antes de Cristo, onde são observados os primeiros esboços.

Tratando-se de fato histórico, a hermenêutica aparece no campo científico por meio dos intérpretes da Bíblia, pois estes perceberam que não poderiam realizar a transcrição literal das escrituras. Assim, tomaram por base a necessidade de enxergar o texto no seu contexto, interpretando a sua simbologia linguística, conforme defendido por Strecker; Schnelle (1997, p. 170) ${ }^{1}$ :

La necesidad de una reflexión metodología de esta naturaleza sobre la interpretación de un texto surge de la constatación de la distancia histórica que nos separa de los escritos neo testamentarios. Estos expresan la fe de los primeros cristianos, no atemporal o ahistóricamente, sino en conceptos linguísticos y conceptuales relacionados con el pensamiento y las experiencias de los hombres de su tiempo.

Os autores acima atribuem ao Judaísmo Bíblico, na figura do Rabino Hillel, "sete regras" para a interpretação do Antigo Testamento, também conhecidas como "As Sete Regras de Hillel" que de imediato espalharam-se por muitos lugares. Resumidamente, as Sete Regras de Hillel afirmavam que, para se realizar uma interpretação de textos bíblicos, deveriam ser

\footnotetext{
${ }^{1} \mathrm{~A}$ necessidade de uma reflexão metodológica dessa natureza sobre a interpretação de um texto surge da verificação da distância histórica que nos separa dos escritos do Novo Testamento. Eles expressam a fé dos primeiros cristãos, não atemporal ou a-historicamente, mas em conceitos lingüísticos e conceituais relacionados ao pensamento e às experiências dos homens de seu tempo. (Tradução dos autores)
} 
observados os seguintes pressupostos: ad minori ad maius (do menos para o mais) ou, do mais fácil ao mais difícil (e também o contrário); per analogiam (por analogia, no que se refere a conclusão, onde deve-se procurar por palavras de mesmo significado; a reunião de passagens (do texto) semelhantes onde seja possível a construção de uma "família"; conclusão principal como resultado de citações do próprio texto; interpretação do geral para o particular (e também ao contrário); a explicação mais aproximada de uma frase usando-se outra como referência e, por fim, a dedução do contexto, onde se tem uma interpretação que parte do contexto de uma afirmação. (Strecker; Schnelle, 1997, p.171).

Os mesmos autores também consideram o método hermenêutico de Pablo, um antigo fariseu que dominava as técnicas de Hillel e, também, as técnicas helenistas. Assim, Pablo assimilou algumas possibilidades oferecidas por Hillel (principalmente a primeira,"aminori ad maius" e a segunda possibilidade) trazendo também, as interpretações de fatos futuros como, por exemplo, o Apocalipse. Conforme Strecker; Schnelle (1997) o Alexandrino Orígenes (185 - 253), um dos teólogos melhor reconhecido pelos filósofos pagãos da época, escreveu comentários sobre os principais livros do Antigo Testamento e, em sua interpretação destes pelo método alegórico, onde por sua influência, este tornou-se "o método eclesiástico de interpretação das Escrituras" através da antonomásia ${ }^{2}$.

Outro hermeneuta que trouxe importante contribuição com a sua "Doctrina del cuádruple sentido de la Escritura" foi Juan Casiano (360 - 435) onde propõe uma interpretação dividida primeiramente no sentido literal dos escritos, seguido de uma interpretação alegórica onde discorre sobre a verdade da fé em Jesus Cristo contida no texto; o terceiro passo seria uma interpretação tropológica, ou moral, dos escritos onde destaca as normas do comportamento Cristão contidas nos textos e, por último, através da escatologia (ou análise do fim do mundo), busca indícios da continuidade dos justos e perfeitos nos Reino de Deus após o juízo final. Acerca disso, Strecker; Schnelle (1997, p. 175) 3 conclui que:

\footnotetext{
${ }^{2}$ A antonomásia consiste, em retórica, na substituição de termo sem textos por outros que muitas vezes nada tinham a ver, morficamente, com o nome substituído.

3 “O fundamento da doutrina do sentido quádruplo da Escritura foi a convicção de que na Bíblia, não apenas as palavras, mas ela mesma, sua materialidade transborda significado. O objeto mais importante deste método de interpretação é relacionar o máximo possível as afirmações da Escritura com todos os campos da vida." (Tradução dos autores).
} 
El fundamento de La doctrina del sentido cuádruple de la Escritura fuela convicción de que, en la Bíblia, no solo las palabras, sino ella miesma, su materialidade, rebosa significado. El objeto de este importante método interpretativo es relacionar lo más posible las afirmaciones de la Escritura con todos los campos de la vida.

Ainda devemos destacar neste estudo o método hermenêutico de Martin Luther, o qual trouxe à discussão o questionamento a respeito das interpretações alegóricas por analogia, contestando inclusive a doutrina do quádruplo sentido das Escrituras. Segundo Strecker; Schnelle (1997), ao rechaçar estas interpretações, Lutero trouxe à tona a sua teoria da interpretação bíblica o literal issensus, em que seria correto e traria consigo a vida, o apoio, a força, a doutrina e a arte. No entendimento de Lutero, a interpretação haveria de limitar-se ao sentido literal e imediato dos escritos. Com isso, mostram os autores que "[...] la Escritura es por sé misma lo más cierto, lo más facilmente accesible, lo que mejor se entiende, la que se interpreta a sí mesma, la que examina, juzga e ilumina todas las palabras.”(Strecker; Schnelle, 1997, p. 177) ${ }^{4}$.

O princípio da interpretação é, portanto para Lutero, a divisão da Palavra de Deus entre a lei e o Evangelho, pois o conhecimento sobre a Teologia depende de um autêntico conhecimento da Lei e das Escrituras. No entanto, é pela obra do teólogo alemão Friederich Daniel Ernst Schleiermacher: Hermenêutica: Arte e Técnica de Interpretação (2000) que o método hermenêutico consegue transpor uma antiga distinção histórica entreo sacro (que tratava da Teologia) e o profano (que tratava da Filologia), incluindo ainda em seus estudos as ciências orientais e a literatura. Para além disso, na mesma obra, Schleiermacher esboça uma Teoria Hermenêutica Geral que se concentra nos signos linguísticos e, supera a discussão da doutrina do quádruplo sentido das Escrituras.

Com o pensamento de Schleiermacher (2000), a Hermenêutica afasta-se definitivamente da Exegese ${ }^{5}$ Bíblica para visar uma "apreensão das significações intencionais das atividades históricas concretas do homem”. Assim, o autor visualiza a união indissolúvel de pensamento e da linguagem, tanto como a inexistência de uma linguagem universal, pois segundo o próprio, esta é “um infinito indeterminado”, pois é histórica.

\footnotetext{
4 “A Escritura é, por si mesma o mais certo, o mais facilmente acessível, o que melhor se entende, a que se interpreta a si mesma, a que examina, julga e ilumina todas as palavras.” (Tradução dos autores).

${ }^{5}$ Exegese é uma análise, interpretação ou explicação detalhada e cuidadosa de uma obra, um texto, uma palavra ou expressão. Etimologicamente, este termo se originou a partir do grego exégésis, que significa "interpretação", "tradução" ou "levar para fora (expor) os fatos".
} 
A linguagem, por sua vez, é base de uma organização esquemática, a qual interpreta o real. É interessante ainda destacar que na base dos conceitos e juízos, Schleiermacher (2000, p.18) intui uma circularidade ${ }^{6}$ onde "o juízo pressupõe conceitos, e os conceitos, por sua vez, pressupõem juízos". Nessa configuração, interpreta-se o pensamento como se fosse uma reflexão entre o universal e o particular, onde o universal aparece sob uma forma particular e, o particular, por sua vez, manifesta-se no universal.

No decorrer deste artigo ver-se-á que, na elaboração da proposta de Hermenêutica em Schleiermacher, leva-se em consideração ainda a Dialética e a Gramática, onde: a Hermenêutica mostra os limites da Dialética; a Dialética mostra as possibilidades da Hermenêutica e, ambas possuem relação de interdependência com a Gramática, já que esta proporciona o entendimento e a comunicação linguística. A Teoria Hermenêutica de Schleiermacher foi alavancada pela necessidade que se tinha à época de, principalmente interpretar textos clássicos por meio da apreensão do pensamento integrante em um determinado discurso.

Deste modo, tendo por referência os estudos de Schleiermacher (2000) é elaborado um sistema estruturado do método Hermenêutico e este passa então a constituir-se como ciência. Com isso, passa a contar não somente com as "regras e uma explicação" ao procedimento de interpretar, mas agora também traz consigo "as razões" das regras e dos procedimentos, o que eleva a Hermenêutica ao patamar da compreensão geral.

Através de seus movimentos Schleiermacher (2000) desloca o eixo do entendimento sobre Hermenêutica do domínio técnico e científico para o domínio filosófico, com o argumento de que a compreensão está interligada com o falar e o pensar, visto que:

[...] a arte de falar e compreender (correspondente) estão contrapostas uma à outra, e falar é, porém, apenas o lado exterior do pensamento, assim a hermenêutica está conectada com a arte de pensar e, portanto, é filosófica. (Schleiermacher, 2000, p. 15)

\footnotetext{
${ }^{6}$ Indicaremos seis níveis das circularidades: entre a ocorrência de uma palavra e a ordem da frase; entre a frase e o discurso; entre o discurso e a obra completa do autor; entre a obra e o conjunto da vida total do autor, bem como o conjunto de literatura da sua época; entre a vida e o conjunto da obra do autor e a mentalidade geral da época e, por fim, entre o espírito da época do autor e o espírito da época do intérprete. (conforme artigo intitulado "Le Rôle du sujetdans I'nterprétaton. Une nouvelle lecture de Schleiermacher avec Manfrd Frank, in revue Philosophique de Louvin, n. 84 (1991) (606-634).
} 
Deste modo, pode-se preliminarmente afirmar: a concepção de Hermenêutica, segundo Schleiermacher (2000, p.15), é a "arte da compreensão correta do discurso de um outro" e que, em cada linha, esta compreensão deve ser incessantemente desejada e buscada.

Da mesma forma, a concepção empreendida por Schleiermacher (2000, p. 16) diz que esta é "uma reconstrução histórica e divinatória dos fatores objetivos e subjetivos de um discurso falado ou escrito". No método hermenêutico divinatório, busca-se uma apreensão imediata e a compreensão ocorre objetiva ou subjetivamente, de forma provisória, pois o entendimento deste discurso ${ }^{7}$, invariavelmente, não ocorre de forma simultânea e integral.

O sucesso no estudo hermenêutico de um discurso, sob o ponto de vista de Schleiermacher, terá maiores chances de êxito somente na utilização do método comparativo onde se parte do genérico e busca-se detectar contrastes admitindo-se aqui que já se tenha uma pré-compreensão do discurso, falado ou escrito, que se pretende analisar.

$\mathrm{O}$ autor ressalta que, ainda é necessário estabelecer que ambos os métodos, divinatório e comparação, são complementares, pois uma comparação para ser efetiva enquanto método, só ocorre de forma integral a partir do momento em que já houve um pré-entendimento imediato do discurso em análise. Logo, a apreensão do discurso se dá por meio da compreensão da linguagem ${ }^{8}$ e só inicia-se um estudo hermenêutico pelo estudo do discurso.

Não menos importante neste momento é deixar claro que, conforme o autor, tudo aquilo encontrado ao iniciar um estudo hermenêutico é a linguagem e que, o produto final do estudo será "novamente linguagem". Observando a ideia de Schleiermacher (2000) não se falará neste trabalho de uma linguagem geral e irrestrita, mas sim uma linguagem delimitada pelo discurso de seu autor. Desta forma, a linguagem pode ser entendida como base, uma espécie de tripé, para o estudo hermenêutico pois ela é o objeto, o instrumento e o resultado da hermenêutica.

Embora Schleiermacher não tenha sido o único autor a realizar uma estruturação da Hermenêutica, nosso foco prevaleceu sobre ele, pois foi este autor que em seus estudos observou a importância da compreensão das expressões linguísticas. Para Ele, as percepções abarcadas com relação ao discurso, a linguagem utilizada e às memórias do autor não podem,

\footnotetext{
${ }^{7}$ Entende-se o discurso, falado ou escrito, como "às instâncias de comunicação corretamente presentes" (Thompson, 1990, p. 371).

${ }^{8}$ Uma aproximação do conceito de linguagem é dado por Schleiermacher, (2000, p. 77), onde o autor afirma, entre outras coisas que esta é: "efetuada como discurso. Sem ela, nenhuma manifestação humana seria possível, e nada poderia ser pensado. Pois todo pensar já é um falar, um "falar interior" mediante palavras.”.
} 
sob hipótese alguma, no percurso interpretativo serem ignoradas. Sem esta não se compreende nem o conjunto, nem o detalhe.

Da mesma forma, seria impossível uma interpretação, mesmo que temporária mais próxima da realidade sob rígidas regras sem uma experiência pessoal. Para Schleiermacher (2000, p. 41) há uma grande questão envolvendo tudo isso: “De onde proviria, então, o ponto de partida para o procedimento de comparação, se ele não fosse dado nas tentativas pessoais?".

A esta pergunta, não há uma resposta imediata e determinada, mas sim considerações acerca da Hermenêutica, onde Schleiermacher (2000, p. 41-42) leva a buscar:

[...] nada diferente do que uma passagem constante de um método a outro, a qual deve se aproximar mais e mais de uma coincidência dos dois métodos no mesmo resultado, idêntico àquele instantâneo, se deve surgir ao menos alguma satisfação.

Neste sentido e, para a superação destas dificuldades o autor sugere outro passo na interpretação quando há o questionamento no que diz respeito à interpretação afirmando que as dificuldades são superadas:

[...] apenas por um procedimento comparativo, no qual nós aproximamos [sempre de novo] alguma coisa já compreendida e semelhante ao ainda não compreendido, encerrando assim a nãocompreensão em limites sempre mais estreitos. (Schleiermacher, 2000, p. 42)

Perpassando a ideia de que a Hermenêutica deve se apropriar somente da interpretação de obras literárias e/ou históricas, Schleiermacher desafia a realizar a operação hermenêutica de qualquer discurso, anúncio, notícia, conversação ou problema onde o nível de compreensão não seja satisfatório por parte do operador hermeneuta, como segue:

Quem poderia conviver com pessoas espiritualmente distintas sem que se esforçasse para entender entre as palavras, como nós lemos entre as linhas dos escritos inteligentes e densos, quem não desejaria fazer uma consideração precisa de uma conversação significativa, [...] que não procuraria nesse caso colocar em relevo os pontos salientes e apanhar o seu encadeamento interior, e seguir todas as discretas insinuações? (Schleiermacher, 2000, p. 33) 
Em situações como esta, Schleiermacher (1990) orienta interpretar as conversações significativas $^{9}$ e a maneira como ocorre o desenvolvimento do discurso. Isso tudo corrobora para que se possa interpretar um encadeamento de pensamentos, algo como uma sequência lógica que, desta forma poderia trazer um recorte de determinado momento do autor. Se mesmo assim, este encadeamento do pensamento do "dono do discurso" não for apreendido, pode-se estar diante de um problema sem solução para a Hermenêutica.

Para que não haja desilusão diante de situações onde a apreensão não ocorrer dentro de um tempo razoável, há que se entender, por outro lado, que conforme destaca Schleiermacher (1990, p. 35) "[...] enquanto uma única de tais possibilidades não estiver completamente descartada, não se pode falar do conhecimento necessário".

Seguindo a ideia do autor, deve-se através da compreensão gradual das minúcias, dos fragmentos e de tudo aquilo que se organiza a partir destes, formar um juízo provisório. Desta forma, diante de avanços, a cada etapa podem surgir novos começos, novas incertezas, e o que for possível estruturar a partir disso é sempre um juízo mais completo em relação ao anterior de tal maneira que, quanto maior é o progresso hermenêutico, maior é o grau de entendimento em relação ao todo até que, ao final, cada um destes contornos é finalmente trazido à luz da compreensão.

Acerca das obras passíveis de interpretação, Schleiermacher (1990, p. 38) afirma: “[...] cada obra é um particular/singular que pertence a um todo chamado de literatura. A literatura, por sua vez, é formada por outras obras de conteúdo similar que devem ter como referencial a linguística".

Assim, pode-se dizer que não se deve perder de vista outro importante elemento nesta análise: o aspecto psicológico em relação ao autor onde entende-se: “[...] aquele hermeneuta que acompanhou o autor e sua obra em vida terá condições muito mais facilitadas em relação ao que busca a interpretação em um momento histórico posterior” (Schleiermacher, 1990. p. 39).

Ainda sobre a literatura, com base nas ideias de Schleiermacher (1990), possuir absoluta riqueza em exemplos, torna-se por vezes complexa e, portanto, se faz necessário uma cuidadosa seleção dos exemplos utilizados para o desenvolvimento de um argumento

\footnotetext{
${ }^{9}$ Para Schleiermacher $(2000$, p.34) as conversações significativas são aquelas em que ocorre a presença imediata do falante, que assim manifesta a participação de todo o seu ser espiritual.
} 
metodológico que possibilite a interligação dos diversos métodos existentes. Neste ponto, o enfoque da Hermenêutica de Profundidade traz possibilidades significativas do ponto de vista da interpretação.

\section{A Hermenêutica de Profundidade (HP)}

A perspectiva da $\mathrm{HP}^{10}$ pretende ser um marco referencial metodológico onde John Thompson traz uma série de argumentos relativos à análise das formas simbólicas ${ }^{11} \mathrm{e}$, assim:

[...] coloca em evidência o fato de que o objeto de análise é uma construção simbólica significativa e exige uma interpretação. Por isso, devemos conceder um papel central ao processo de interpretação[...]. Mas as formas simbólicas estão também inseridas em contextos sociais e históricos de diferentes tipos; e sendo construções simbólicas significativas, elas estão estruturadas internamente de várias maneiras. (Thompson, 1990, p. 355)

O entendimento de Thompson (1990) sobre as ciências, leva a compreensão de que todas as ciências, sejam elas sociais ou naturais exigem, em algum momento, compreensão e/ou interpretação de algo. Essa certeza, porém, não pode ser encerrada em si, visto que neste trabalho o horizonte e o objeto de pesquisa são por si um "território pré-interpretado ${ }^{12}$ ". Segundo o autor, o mundo sócio-histórico, o qual propõe-se a investigar:

[...] não é apenas um campo-objeto que está ali para ser observado; ele é também um campo-sujeito que é construído, em parte, por sujeitos que, no curso rotineiro de suas vidas quotidianas, estão constantemente preocupados em compreender a si mesmos e aos outros, e em interpretar ações, falas e acontecimentos que se dão ao seu redor. (Thompson 1990, p.358)

À medida que o principal objetivo é avançar em relação ao método, Thompson (1990, p. 362) alerta para um fato que não pode ser ignorado, pois para ele este processo interpretativo: “[...] pode ser, e de fato exige que seja mediado por uma gama de métodos explanatórios ou objetivantes.". Prossegue o autor, fazendo a ressalva:

\footnotetext{
${ }^{10}$ A partir deste momento da pesquisa, a Hermenêutica de Profundidade será chamada de forma simplificada, por suas iniciais "HP", conforme Thompson (1990, p. 355).

${ }^{11}$ Entende-se formas simbólicas, conforme Thompson (1990, p. 358), como construções significativas que exigem interpretações, podendo elas se apresentar na forma de ações, falas ou textos que, justamente por serem construções significativas, podem ser também compreendidas.

${ }^{12}$ Um território pré-interpretado, conforme Thompson (1990, p.358), é uma forma simbólica que já é fruto de uma interpretação anterior e, ao ser interpretado novamente, terá como resultado uma "interpretação da interpretação" ou, simplesmente, uma re-interpretação.
} 
[...] "explanação" e "interpretação" não devem ser vistas, como o são muitas vezes, como termos mutuamente exclusivos [...]; antes, podem ser tratados como momentos complementares dentro de uma teoria compreensiva interpretativa, como passos que se apoiam mutuamente [...].” (Thompson 1990, p. 362)

Do ponto de vista da HP, é então fundamental a compreensão de que o objeto de investigação é um campo pré-interpretado e deve-se, portanto, levar em consideração os modos com os quais as formas simbólicas foram interpretadas pelos sujeitos que constituem assim o campo-sujeito-objeto ${ }^{13}$. Com isso, é necessário, neste momento, empenhar-se no entendimento e apreensão das maneiras como as formas simbólicas em estudo foram interpretadas por aqueles que as produzem ou as recebem no decorrer do seu quotidiano. Thompson (1990, p.363) trata este momento como “indispensável ao enfoque da HP” e, observa ainda que por meio de "[...] entrevistas, observação participante e outros tipos de pesquisa etnográfica, podemos reconstruir as maneiras como as formas simbólicas são interpretadas e compreendidas nos vários contextos da vida social”.

Não menos importante que as afirmações anteriores é dizer que essa própria reconstrução já se constitui em um processo interpretativo, nada mais que uma interpretação do entendimento quotidiano ao qual Thompson (1990, p. 363) chamou de interpretação da doxa ${ }^{14}$. Desconsiderar estes contextos quotidianos, conforme o autor, constitui uma falta grave na interpretação e investigação do campo-objeto de interesse da pesquisa.

Por outro lado, Thompson (1990, p. 364), afirma que também é importante destacar que a interpretação da doxa "não é o fim da investigação e sim seu ponto de partida, pois existem vários outros pontos que não devem ser desconsiderados".

Seguindo o raciocínio do autor, para que ocorram avanços na investigação, é necessário compreender que dentro do enfoque da HP existem três procedimentos principais os quais se constituem em dimensões de análise distintas em um processo de interpretação complexo como a HP pretende apresentar-se. A figura 1 traz as várias fases do enfoque da HP, conforme a ideia de Thompson.

\footnotetext{
${ }^{13}$ Segundo Thompson (1990, p. 359) o termo "campo-sujeito-objeto" refere-se aos sujeitos que já interpretaram o "campo-objeto" da pesquisa e assim, também fazem parte da análise/interpretação.

${ }^{14}$ Segundo Thompson (1990, p. 363), a interpretação da doxa (ou hermenêutica da vida quotidiana) é uma interpretação das opiniões, crenças e compreensões que são sustentadas e partilhadas pelas pessoas que constituem o mundo social.
} 
Figura 1 - Formas de Investigação da HP

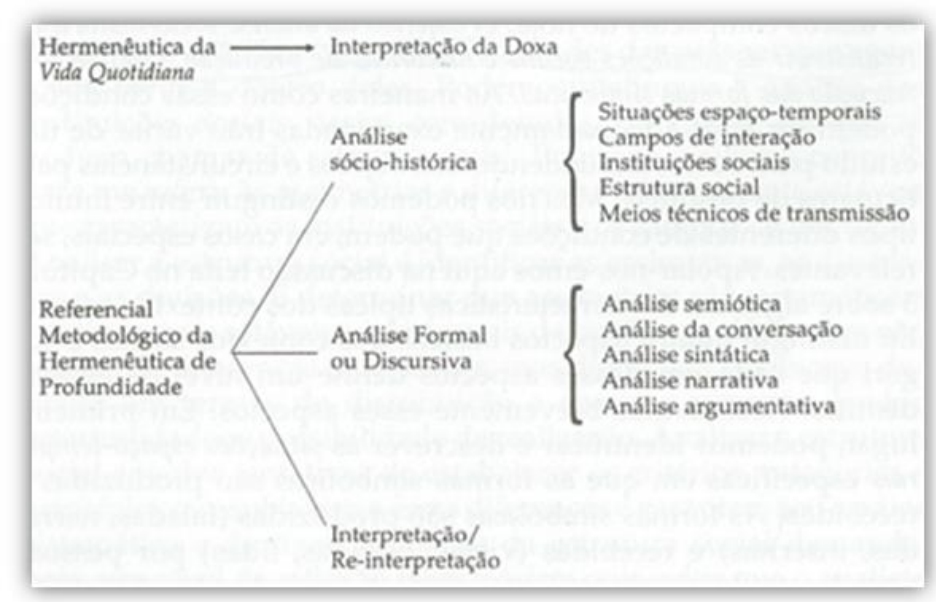

Fonte: THOMPSON (1990, p. 365)

O esquema apresentado na figura 1 é, conforme Thompson (1990), preliminarmente ilustrativo, sendo que a forma de como estas três fases serão aplicadas depende, sobretudo, da análise e entendimento do pesquisador. Dentro de cada uma destas podem ocorrer alguns métodos mais eficazes que outros onde tudo dependerá do objeto específico ou das circunstâncias da investigação.

As formas simbólicas são produzidas e comunicadas sob condições sócio-históricas específicas e, mesmo aquelas que por vezes representam certa atemporalidade, estão assim caracterizadas. Desta forma, Thompson (1990, p. 366) afirma: “o objetivo da análise sóciohistórica é, reconstruir as condições sociais e históricas de produção, circulação e recepção das formas simbólicas".

Avançando no entendimento das ideias de Thompson referentes à análise sóciohistórica, chega-se às instituições sociais, as quais formam um conjunto de relativa estabilidade de regras, recursos e relações sociais estabelecidas pelos próprios através de posições e trajetórias. As instituiçõos sociais estão situadas no interior dos campos de interação e interagem com eles, formando outros campos de interação e, com isso fixando novas posições e, trajetórias. Para Thompson (1990, p. 367) proceder com uma análise destas instituições, é "reconstruir os conjuntos de regras, recursos e relações que as constituem, é traçar o seu desenvolvimento através do tempo e examinar práticas e atitudes das pessoas que agem a seu favor e dentro delas".

Quando, com base em Thompson (1990), compara-se a relativa estabilidade das diferenças existentes entre as instituições sociais e os campos de interação, se está analisando 
a "estrutura social". Posto isso, pode-se afirmar que analisar a estrutura social é determinar diferenças coletivas em termos da distribuição e acesso a recursos e oportunidades de viabilização. Esta análise envolve ainda um ensaio de visualização de critérios, grupos e juízos que possam garantir um caráter sistematizado e perene; onde se deve destacar ainda o seu nível teórico de reflexão, com o objetivo de propor modelos que “[...] ajudem a organizar e iluminar a evidência das assimetrias e diferenças sistemáticas da vida social." (Thompson 1990, p. 367).

Existe ainda, um conjunto de particular relevância para que se possam investigar as formas simbólicas que Thompson (1990, p. 368) designou de "meios técnicos de construção de mensagens e transmissão". No entendimento de que as formas simbólicas são transmitidas entre os sujeitos, há o entendimento de que é utilizada alguma forma de troca destas, que pode variar desde conversações face-a-face ou, até mesmo através de esquemas mais complexos como em comunicadores instantâneos como, por exemplo, aqueles utilizados nos smartphones, os quais, nesta pesquisa, serão chamados de meios técnicos de transmissão.

Obviamente, assim como afirma Thompson (1990, p. 368) estes meios técnicos de transmissão não existem no vácuo; “[...] eles estão sempre inseridos em contextos sóciohistóricos particulares", pressupondo então esquemas de codificação e decodificação destas mensagens que, por necessitarem de certos recursos, conhecimentos e/ou habilidades, não estão igualitariamente distribuídos entre os sujeitos, onde se pode afirmar que, por vezes, esta desigualdade pode estar relacionada com "a regulação, produção e circulação das formas simbólicas" Thompson (1990, p. 368).

Outrossim, Thompson, na sequência, chama a atenção para que os meios técnicos de construção e de transmissão de mensagens não pode se constituir apenas numa investigação técnica, mas deve procurar elucidar os contextos sociais em que estão inseridos e empregados.

A pesquisa sócio-histórica e suas variantes são tentativas diferentes utilizadas para contextualizar socialmente as formas simbólicas. Por sua vez, a produção, a circulação e até mesmo a recepção destas formas simbólicas estão associadas aos processos que ocorrem dentro de contexto sociais estruturados e historicamente específicos. A produção destas formas simbólicas ocorre mediante regras e recursos disponíveis ao autor, sendo orientada à circulação dentro, também, de um campo social. Esta orientação pode possuir uma estratégia 
clara ou implícita, dependendo sempre do contexto social por onde pretendam seus produtores, que ela circule.

Deste modo, Thompson (1990, p.369) afirma que a função primeira da HP é:

[...] reconstruir as condições e contextos sócio-históricos de produção, circulação e recepção das formas simbólicas, examinar as regras e convenções, as relações sociais e instituições, e a distribuição de poder, recursos e oportunidades em virtude das quais esses contextos constroem campos diferenciados e socialmente estruturados.

Cabe ainda observar que expressões e objetos que porventura orbitem o campo de estudo devem ser entendidos como formas simbólicas construídas e assim, também passíveis de interpretação. Por apresentarem uma forma articulada e complexa exigem, pois, outra forma de análise, pois estas são, por sua vez, produtos de ações ou discursos que baseiam-se em uma série de esquemas disponíveis ao seu mentor. Assim, deve-se compreender estas formas simbólicas complexas como produtos que, em virtude deste esquema estruturado tem por capacidade e, por objetivo versar sobre algo.

Em virtude deste esquema estruturado e de sua forma articulada complexa, estas formas simbólicas possuem uma propriedade de irredutibilidade, exigindo assim outro olhar sobre seus padrões. Aqui, entende-se necessária uma forma diferente de análise, a qual Thompson (1990, p. 369) chamou de "análise formal ou discursiva" que trata de estabelecer:

[...] as bases para um tipo de análise que está interessada primariamente com a organização interna das formas simbólicas, com suas características estruturais, seus padrões e relações. [...] é um empreendimento perfeitamente legítimo, na verdade, indispensável; ele é possível pela própria constituição do campo objetivo.

Considerando estas possibilidades descritas acima, cabe-nos observar que, diante da necessidade de analisar toda esta formulação, foi necessário lançar mão da técnica que Thompson define como semiótica. A análise semiótica trata das relações entre os elementos que compõem a forma simbólica, também chamados de signo, e de como estes elementos se relacionam entre si ou, como estes elementos se relacionam com os demais.

Através da análise semiótica Thompson (1990) foi possível avançar, conforme a necessidade, na compreensão de constituição interna de determinada forma simbólica, não sendo assim prioridade desta a observação, a análise sistemática e seu aspecto referencial, ou seja, como ocorre a combinação de elementos para que se diga algo sobre alguma coisa. 
Estando ciente destas limitações impostas pela análise semiótica, é importante lembrar que este é um passo na caminhada para uma interpretação mais completa.

No entanto, Thompson (1990) destaca outras formas de interpretação são possíveis através da HP, as quais não podem ser desprezadas, pois representam importantes meios de interpretação das expressões linguísticas. Elas permitem, de certa forma, uma análise sobre a comunicação no dia-a-dia, como por exemplo as interações em uma sala de aula, um programa de televisão, etc.

A saber, o primeiro método de análise das expressões linguísticas descrito por Thompson (1990) foi a análise de conversação, onde deve-se estudar, principalmente, as situações concretas onde a interação linguística ocorre e, ainda o mecanismo do processo onde os integrantes produzem uma certa ordem estrutural, a qual organiza esta interação e possibilita produzir um ordenamento por meio da aplicação de procedimentos rotineiros.

Outra maneira da qual se pode lançar mão quando estuda-se as estruturas internas de um discurso é a análise argumentativa a qual pode ser definida como "[...] cadeias de raciocínio que podem ser reconstituídas de várias maneiras” (Thompson, 1990, p. 374). Estas cadeias de raciocínio, por sua vez, possibilitam ao analista organizar o discurso através de afirmativas e tópicos e após estabelecer relações entre estes.

A última fase do enfoque da HP ao qual Thompson (1990) chamou de Interpretação/reinterpretação, que ora pode ser confundida com a análise, é apenas parte integrante deste aspecto. A interpretação é, e deve ser vista como um complemento necessário à análise formal ou discursiva, pois em sua essência, a análise apresenta um enfoque parcial do estudo das formas simbólicas ou discursivas.

Para, além disso, e, ao passo que, mesmo rigorosos e sistemáticos “[...] os métodos de análise formal e discursiva [...], eles não podem abolir a necessidade de uma construção criativa do significado, isto é, de uma explicação interpretativa do que está representado ou do que é dito" (Thompson, 1990, p.375).

Assim a reinterpretação, e também a interpretação, são operações sempre arriscadas, pois é admissível a existência de conflitos e, um espaço para a discussão, pois segundo a ideia de Thompson (1990, p. 376): “A possibilidade de um conflito de interpretação é intrínseco ao próprio processo de interpretação.”. Este conflito pode surgir não apenas das interpretações distintas entre analistas que utilizam a HP, mas, também, entre sujeitos que se utilizam da HP 
e outros, que constituem o mundo sócio-histórico e a isto, Thompson (1990, p. 375) chama de "potencial crítico da interpretação", onde as divergências se reúnem e se apresentam e se encontram entre suas pré-interpretação e reinterpretação.

Por fim, e ainda dentro da ideia do autor, cabe considerar que a HP oferece um esquema onde as formas simbólicas podem ser analisadas de uma maneira em que é evidenciado o seu caráter histórico e social e que, apresenta estruturas através das quais algo é representado ou dito. Thompson (1990) lembra ainda que a HP impede que o pesquisador caia em armadilhas de métodos particulares os quais levariam facilmente a falácias ou reducionismos, que negligenciariam as condições históricas e processos quotidianos de construção e recepção destas formas.

O referencial acerca da HP, não limita só o estudo das formas simbólicas, mas também de suas estruturas, que nos levam ao estudo da disciplina escolar, no nosso caso a Matemática. Deve contemplar também a interpretação histórica dos fatos que influenciaram o seu contexto, tendo como ponto de partida a instituição escolar.

\section{Refletindo sobre as aproximações e distanciamentos}

Realizada a abordagem das principais características da Hermenêutica e da Hermenêutica de Profundidade, relevantes para os estudos historiográfico em educação, podemos perceber o primeiro aspecto de aproximação entre os dois métodos: o fato da HP ser uma metodologia que emerge a partir do método hermenêutico de interpretação, o que sugere que, ao menos em sua essência, as duas metodologias são significadamente semelhantes pois em sua essência, ambas podem ser compreendidas como "a arte da interpretação".

No entanto, também é possível constatar que os processos de análise da Hermenêutica

e da HP apresentam seus distanciamentos. Ao passo que o método hermenêutico está enraizado na interpretação com embasamento teológico, através da compreensão da exegese bíblica, de escrituras filosóficas que exigem do leitor um entendimento desta leitura simbólica (e de suas alegorias) ou de escrituras antigas ligadas a filologia, a HP traz a propriedade de interpretar as formas simbólicas a partir do contexto social e histórico em que estas formas simbólicas foram compostas. Dessa forma, a HP nos fornece um novo conceito de interpretação que é a avaliação dos aspectos sociológicos.

Outro ponto em que ocorre um distanciamento entre as duas propostas metodológicas é o fato de que a Hermenêutica indica que o pesquisador pode em algum momento, diante de 
alguma impossibilidade de apreensão das "conversações significativas" (ou do encadeamento das ideias que estas trazem consigo) estar a frente de um problema indissolúvel para este método de interpretação. Já a HP, que traz consigo a análise das formas simbólicas, sugere que como tais, estas são construções significativas (que podem ser fruto de ações, falas ou textos) e, por serem significativas podem ser compreendidas, não deixando assim margem para que não ocorram interpretações.

Tratando-se exclusivamente da Educação Matemática podemos compreender que a HP seria uma alternativa metodológica interessante a ser seguida no momento da realização de um estudo historiográfico, pois através dela é possível elaborar uma estratégia de pesquisa onde o investigador escolhe suas formas simbólicas de pesquisa e assume um personagem na sociedade que as constituiu, possibilitando que sua pesquisa traga ao leitor maior fidedignidade dos fatos que propuseram a elaboração de tais formas simbólicas.

Entretanto, quando é requerida uma análise mais filosófica dos significados, onde estes são o principal objeto de estudo, baseando-se na argumentação e arguição para a interpretação e reescrita da história, cabe ao pesquisador utilizar a Hermenêutica para embasar sua estratégia de pesquisa.

A arte de interpretar símbolos é um notório fator comum entre as duas metodologias de pesquisa. Sendo a HP um ramo desenvolvido a partir da Hermenêutica, apresentam ambas estratégias de interpretação em comum, muitas vezes sendo mais claras as suas aproximações e de difícil percepção um estabelecimento de fronteiras e afastamentos entre ambas.

\section{Considerações Finais}

Por certo, a pesquisa histórica é uma arte que demanda tempo, disposição e muita sensibilidade do pesquisador. Ademais, uma fundamentação teórica adequada é ferramenta importante no percurso da escrita e que, se utilizada de maneira concisa pode levar a resultados relevantes.

No que diz respeito ao marco teórico em pesquisas historiográficas, seja este o da Hermenêutica ou da HP, é importante dizer que, embora, via de regra, nossa ênfase tenha como foco as obras escritas, seu campo de aplicação não se resume somente a estas, podendo, a critério do investigador ser utilizada para fatos e/ou acontecimentos, rastros, e qualquer outro tipo de registro passível de interpretação. 
Neste artigo, buscamos chamar a atenção para o uso da Hermenêutica como uma possibilidade de marco teórico para pesquisas historiográficas no ensino da matemática. Logicamente não buscamos com isso apontar "o rumo", mas sim "um rumo" para aqueles pesquisadores que dedicam seus esforços a esta linha de investigação.

Desta forma, entendemos que, através deste escrito, podemos colaborar para a discussão acerca não só da pesquisa historiográfica, mas, também, do ensino da matemática como um todo, pois à partir do momento que compreendemos como os processos se desenvolveram é possível, através do entendimento destas estruturas, pensar em alternativas viáveis e, que possam contribuir para que a educação e o ensino atinjam novos e melhores patamares.

\section{Agradecimentos}

O presente trabalho foi realizado com o apoio da Coordenação de Aperfeiçoamento de Pessoal de Nivel Superior - Brasil (CAPES) - Código de Financiamento 001. Por isso agradecemos especialmente a CAPES por oportunizar este estudo.

\section{Referências}

Huff. A. A. (18 - 03 - 08). A história do ensino de Matemática nas escolas públicas municipais de Canoas de 1940 a 2016. [Dissertação de Mestrado]. Universidade Luterana do Brasil. Canoas, Brasil.

Rosso. F. L. (18 - 04 - 27). Um estudo a partir da disciplina de Matemática no currículo de um Curso Técnico em Novo Hamburgo/RS: relações de contexto histórico no currículo escolar. [Dissertação de Mestrado]. Universidade Luterana do Brasil. Canoas, Brasil.

Schleiermacher, F. D. E. (2000). Hermenêutica: Arte e Técnica de Interpretação. Petrópolis, Brasil. Editora Vozes.

Strecker, G.; Schnelle, U. (1997). Introducción a laexégesisdelNuevo Testamento. Salamanca, España. EditorialSigueme.

Thompson, J. B. (1990) Ideologia e Cultura Moderna: Teoria social crítica na era dos meios de comunicação de massa. Petrópolis, Brasil.Editora Vozes.

Valente, W. R. (2002, novembro) A Matemática Escolar: Perspectivas Históricas. [arquivo pdf]. Recuperado de:http://www.sbhe.org.br/novo/congressos/cbhe3/Documentos/Individ/ Eixo1/030.pdf 